\title{
SOCIALIZACIÓN: ¿FAMILIA VS ESCUELA?
}

\author{
Mg.Vicky Gucvara Granados
}

\begin{abstract}
RESUMEN
la función central de las escuelas $y$ de las familias es la formación y educación de los niños, una tarea en común que debería por sí misma asegurar una estrecha cooperación $y$ apoyo mutuo. Sin embargo, en vez de utilizar de manera conjunta sus recursos para solucionar el problema del niño con el mayor éxito, se establece el escenario de una relación deteriorada entre ambas partes, en la que cada una, mientras hace lo que considera mejor para el niño, mina la autoridad $y$ efectividad de la otra.
\end{abstract}

\section{ABSTRACT \\ The main task of schools and families is to train and educate children, a common task wh ich should guarantee by itself a clase cooperation and mutual help. Nevertheless instead of using its resources as a whole to salve child problems with success, a deteriorated relationship between both parties is presented as a scene in which every party acts as it considers $t$ he best for the child, undermining the authority and effectiveness ofthe other pa rty.}

\section{PALABRAS CLAVE}

Socialización, familia, escuela, educac ión, formac ión.

\section{KEYWORDS}

Socialization, fa mily, school, education, training.
A lo largo de la historia, sobre todo en los últ imos 25 años, han sucedido importantes cambios y transformaciones en la sociedad a nivel político, social, ideológico y cultural, entre otros. Todos estos cambios, como es de suponerse, también han tenido repe rcus ión en la familia, la escuela y, por ende, también en la socialización.

En el caso ele la acción socializado ra de la familia, por ejemplo, hay un gran incremento ele familias monoparen tales, un gran número de mujeres se han incorporado al mundo laboral, el núcleo familiar cada vez es más reducido, dá ndose un menor número de hermanos; por otra parte, abuelos y tíos conviven en espacios urbanos separados del núcleo familiar; las edades de inicio de la escolaridad no obligatoria cada vez se están adelantando más por razones sociales y familiares $\mathrm{y}$; progresiv amente, se tiene cada vez mayor concienciadelo q ue implica, desde el punto de vista educativo,la existencia ele un hijo.

Para algunos, todos estos cambios producidos en la orga niz ac ión fa mil i ar traerían consecuencias negativas sobre la socialización ele los niños, ya que ahora un porcentaje cada vez mayor de mujeres casadas trabaja fuera del hogar, lo que resta tiempo de presencia de los padres en el domicilio; y por otra parte, los lazos con los parientes q ue no forman parte del núcleo familiar han tendido a debilitarse, lo que conduce a que la so ia lización fam iliar ele los niños sea casi responsabilidad exclusiva de los padres. 
Se sabe que, principalmente durante los primeros años ele vida, la familia y el ambiente escolar son los agentes que más in.fluyen en el desarrollo social del individuo y su proceso educativo. Por lo tanto, es necesario que entre la escuela y la familia exista una estrecha comunicación para lograr una visión globalizada y completa del alumno, cambiando las discrepancias y rivalidades por la unificación ele criterios de actuación y apoyo mutuo en favor del bienestar y desarrollo delos educandos.

La función central de las escuelas y de las familias es la formación y educación de los niños, una tarea en común que debería por sí misma asegurar una estrecha cooperación y apoyo mutuo . Sin embargo, en vez de utilizar de manera conjunta sus recursos para solucionar el problema del niño con el mayor éxito, se establece el escenario de una relación deteriorada entre ambas partes, en la que cada una, mientras hace lo que considera mejor para el niño, mina la autoridad y efectividad dela otra.

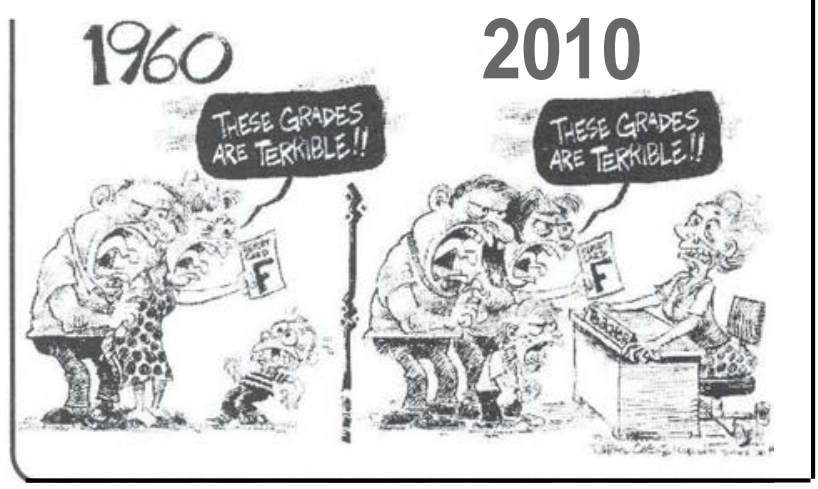

Es importante hacer notar que con mucha frecuencia este tipo de malos entendidos entre la escuela y la familia pueden llevar a largo plazo a causar el rechazo por parte del niño hacia la escuela, a tener problemas más severos de conducta o, inclusive, hasta llegar a la expulsión del niño o adolescente de alguno de esos sistemas. En la mayoría de los casos, estos malos entendidos se dan porque los padres de familia y los docentes no se dan cuenta que conocen al niño en entornos diferentes (el escolar y el familiar) y que puede ser posible que cada parte desconozca sobre el desempeño del niño en ese otro ambiente y por lo mismo la percepción que tengan de ellos puede ser diferente. Esta diferencia en perspectiva constituye un elemento significativo que debe considerarse para prevenir discrepancias.

Por lo tanto, sí un profesor quiere educar realmente, no puede trabajar solo, tiene que contar con el apoyo de los padres de familia, para que los esfuerzos que él realiza en las horas de clase tengan continuidad en el resto del día y viceversa. Un profesor no puede pensar que sólo los alumnos necesitan ser educados, su labor debe proyectarse también hacia la familia y la comunidad, para crear bases sólidas que permitan la integración yla socialización.

Se entiende que el niño es un ser global, y de la misma manera percibe y vive la realidad que le rodea. Por ello, es necesario que los dos ambientes básicos para él, casa y escuela guarden una estrecha coordinación; ya que cuando hay una buena relación, existe más confianza entre padres y profesores; se comunican inquietudes, dudas, deseos sobre el comportamiento y evolución del hijo, y así los docentes conocen mejor a cada niño y son capaces de ayudar e intervenir de manera másefectiva.

Si todos estos cambios que involucran familia y escuela no se manejan en forma adecuada pueden traer consecuencias negativas en el proceso de socialización del niño, quien desde temprana edad necesita cimentar las bases para un desenvolvimiento saludable tanto en su presente como en el futuro.

Es necesario trabajar con un nuevo paradigma en el que se evite la tendencia de catalogar a los padres o a la escuela como equivocados o acertados, así como evitar la tentación de enmarcar a un experto que solucionará todos los problemas. Lo que se requiere ahora es encontrar la forma de aplicar el gran potencial de recursos que todo elemento de un sistema tiene, y suscitar la visión de alternativas desde el punto ele vista del niño, de la familia y de la escuela.

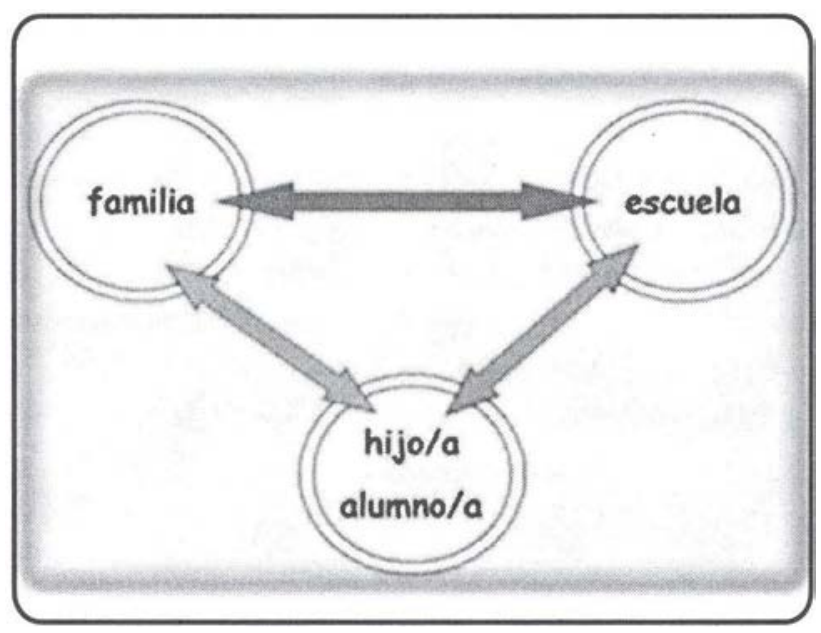

Tanto los padres de familia como los profesores tienen que centrarse en el objetivo común que ambos tienen, que es el de formar hijos/alumnos que desarrollen actitudes y comportamientos que los lleven a una adecuada interrelación interpersonal,

\section{1 un1Fé}


siendo líderes capaces de enfrentar los retos que propone la sociedad. En la actualidad, es de crucial importancia ayudar a que el niño se conozca, se valore y reconozca sus emociones para asegurar una buena relación con las demás personas y de esta manera evitar que puedan convertirse en una víctima más del bullying.

Junto con la familia, la escuela es otro gran agente educativo y socializador de primer orden. En la escuela será donde realmente el niño encuentre el grupo de pares, algo que le permitirá aumentar los entornos en los que se desenvuelve y que incrementará progresivamente (familia, escuela, compañeros, barrio, trabajo...) hasta la inclusión total como ciudadanos que aportan a la sociedad.

De acuerdo con el desarrollo de la comunicación, la escuela cumple el papel fundamental de potenciar la comunicación, así como de compensar los posibles déficits lingüí sti cos del entorno en que vive el niño y proporcionar experiencias y situaciones que amplíen su léxico. De este modo, la escuela constituye el entorno privilegiado donde enseñar las habilidades comunicativas desde el punto de vista más reglado. Es en este contexto donde dichas habilidades forman parte del conjunto de contenidos curriculares obligatorios en todas las etapas educativas. las aulas son los escenarios de acción práctica en las que tiene lugar esta enseñanza ele una forma natural y mediante la experiencia.

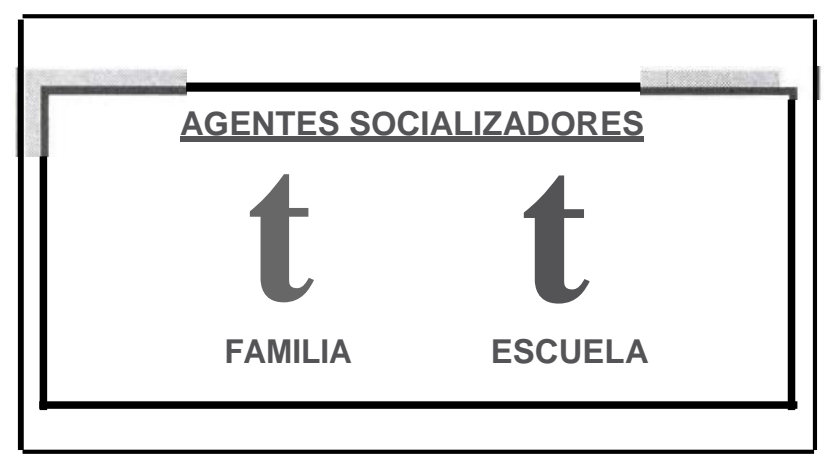

Estos agentes ele socialización también han sufrido transformaciones en las últimas décadas; por ejemplo, mientras que la familia se ha nuclearizaclo y reducido en un alto porcentaje, la escuela abre sus puertas a cada vez más a niños con menor edad.

Gran cantidad de familias se constituyen monoparentales, es decir, familias integradas por solo uno de los progenitores y los hijos. El aumento ele divorcios ha traído consigo que muchas madres deban criar a sus hijos solas. Este hecho contribuye a que la nueva condición de la familia pueda ser una ele las características más significativa de estos tiempos.

Hay dos aspectos muy importantes dentro ele una familia, la crianza y atención a los hijos, que se complica por el incremento de madres que trabajan fuera del hogar. la responsabilidad del padre de ser el proveedor único ele la familia es una realidad que ha perdido casi completa vigencia. En estos tiempos, padre y madre se ausentan no solamente para mantener a sus familias sino para lograr el desarrollo profesional al que se proyectaron. Como resultado de este ausentismo, la convivencia entre padres e hijos puede tornarse permisiva y tolerante.

las familias monoparentales envían a los hijos a la escuela a temprana edad. Si bien este hecho puede convertirse en una ventaja más adelante, es imperativoreconocer quehoy, másqueantes, niños y padres deben ser educados. De hecho, las escuelas hacen esfuerzos, en la actualidad, por estar preparadas para recibir niños a edades cada vez más tempranas.

Martínez y Fuster señalan que entre escuela y la familia debe existir una estrecha comunicación para lograr una visión globalizada y completa del alumno, eliminando en la medida de lo posible discrepancias y antagonismos a favor ele la unificación ele criterios de actuación y apoyo mutuo, ya que por derecho y por deber tienen fuertes competencias educativas $\mathrm{y}$ necesariamente deben estar coordinadas, siendo objeto, meta y res $\mathrm{p}$ on sa bili d ad de ambas instituciones construir una intencionalídad educativa común.

Aunque la familia y la escuela puedan o no coincidir; pero, que en todo caso deben comunicarse, entenderse yapoyarse.

\section{Mg. VickyGuevara Granados}

Magíster en Educación en la especialidad de Tecnología Educativa, Licenciada en Educación Inicial. Aportó datos en el libro Mapas conceptuales. Docente en la UNIFÉ. 